\title{
RESEARCH
}

Open Access

\section{Evaluation of Toxoplasma gondii infection in western Iran: seroepidemiology and risk factors analysis}

\author{
Morteza Mousavi-Hasanzadeh ${ }^{1}$, Hossein Sarmadian², Reza Ghasemikhah ${ }^{3^{*}}$ (D), Mojtaba Didehdar ${ }^{3}$, \\ Maryam Shahdoust ${ }^{4}$, Mahshid Maleki ${ }^{5}$ and Mahdieh Taheri ${ }^{6}$
}

\begin{abstract}
Background: Toxoplasmosis is a parasitic infectious disease, and Toxoplasma gondii is the causative factor of this intracellular protozoan disease. Due to the lack of information about the rate of $T$. gondii in general papulation of Markazi Province in Iran, the current study was conducted to determine the prevalence of toxoplasmosis and the related risk factor analysis in the general population of Markazi Province.

Methods: This cross-sectional study was performed within 6 months on individuals who were referred to diagnostic laboratories in Markazi Province. The demographic and background information of the subjects were collected using a questionnaire. Three milliliters of blood samples was collected from the participants under sterile conditions. The sera were separated and evaluated for levels of anti-Toxoplasma lgG antibody using a commercial enzyme-linked immunosorbent assay (ELISA) method. The collected data were analyzed by the SPSS software using descriptive statistics and chi-square test.

Results: Out of 824 people from the general population of Markazi Province who were investigated in this study, 276 (33.5\%) had anti-Toxoplasma antibodies in their blood. According to the logistic regression model, gender variables, location, marital status, and having a cat at home do not affect the chances of contracting the parasite. Furthermore, the chance of contracting the parasite in 41- to 50-year-olds is 0.85 times the one in the 20- to 30 year-olds. The prevalence of toxoplasmosis in men and women in Markazi Province was 33\% and 34.5\%, respectively.

Conclusion: The mean prevalence of T. gondii infection in the age groups of 20-40, and $\geq 40$ years was estimated to be $24.7 \%$, and $40.8 \%$, respectively. These rates were significantly lower than the national results (44\%, and $55 \%$, respectively). Therefore, regarding to the health authorities, it is necessary to raise the level of awareness of people of the region, especially at-risk groups about the transmittance and prevention methods, and infection risk factors in order to prevent the occurrence of $T$. gondii infection and reduce the prevalence and incidence of the disease.
\end{abstract}

Keywords: General population, Toxoplasmosis, IgG anti-Toxoplasma, Toxoplasma gondii

\footnotetext{
* Correspondence: ghasemikhah@yahoo.com; ghasemikhah@gmail.com ${ }^{3}$ Departments of Parasitology and Mycology, Arak University of Medical Sciences, Arak, Iran

Full list of author information is available at the end of the article
}

(c) The Author(s). 2020 Open Access This article is licensed under a Creative Commons Attribution 4.0 International License, which permits use, sharing, adaptation, distribution and reproduction in any medium or format, as long as you give appropriate credit to the original author(s) and the source, provide a link to the Creative Commons licence, and indicate if changes were made. The images or other third party material in this article are included in the article's Creative Commons licence, unless indicated otherwise in a credit line to the material. If material is not included in the article's Creative Commons licence and your intended use is not permitted by statutory regulation or exceeds the permitted use, you will need to obtain permission directly from the copyright holder. To view a copy of this licence, visit http://creativecommons.org/licenses/by/4.0/. 


\section{Introduction}

Toxoplasma (T.) gondii is an intracellular protozoan with widespread global distribution and it is estimated that one-third of the world's adult population to be infected with the parasite [1].

The infection can occur through consumption of the oocyst-contaminated food, water or raw meat products containing parasite cysts as well as mother-to-the fetus infection. The life cycle of the parasite becomes completed as it transfers from the warm-blooded intermediate hosts to the cat as the final host $[2,3]$.

Only $10-30 \%$ of new toxoplasmosis infections in humans cause clinical symptoms. Symptoms may range from subclinical lymphadenopathy to the fatal central nervous system disease as well as other pathologies in immunodeficient patients. In some congenital infections, some symptoms such as seizures and mental retardation may occur [4].

The seroprevalence of $T$. gondii infection is quite different among human communities which largely depend on the geography, climate, nutrition-related habits, and sanitation levels [5].

In Iran, most studies have been performed to determine the prevalence of $T$. gondii infection in high-risk groups such as pregnant women, premarital women, neonates, and children, and only few studies have been performed on the general population [6-12]. In this regard, Markazi Province is not an exception and as the other provinces in Iran, except of a few limited studies on specific populations, the prevalence of $T$. gondii infection on the general population of this province has not been studied [9].
Altogether, the objectives of this study are to determine the prevalence of $T$. gondii infection and also to analyze the risk factors in the general population of Markazi Province.

\section{Material and methods}

\section{Ethics statement}

This study was conducted after obtaining permission from the Ethics Committee of Arak University of Medical Sciences under the number of IR.ARAKMU.REC.1396.15. At the beginning of the study, a signed informed consent form was obtained from each of the under-study individuals.

\section{The study area}

This cross-sectional study was carried out from May to October 2017, in six cities containing Arak, Khomain, Khondab, Mahallat, Komijan, Delijan, located in Markazi Province, western Iran (Fig. 1).

The study region has a variety of climates due to its high mountains and adjacent to the central border of the country. Gardening and animal husbandry are common in all mentioned areas except of Arak city which is an industrial area.

\section{Sampling and sociodemographic assessment}

This cross-sectional study was performed within 6 months on individuals who referred to laboratories affiliated with Arak University of Medical Sciences, in Markazi Province. The number of samples was calculated based on the official population statistics of each city in this province. A questionnaire was used to collect demographic information including age, gender, marital status, and residence

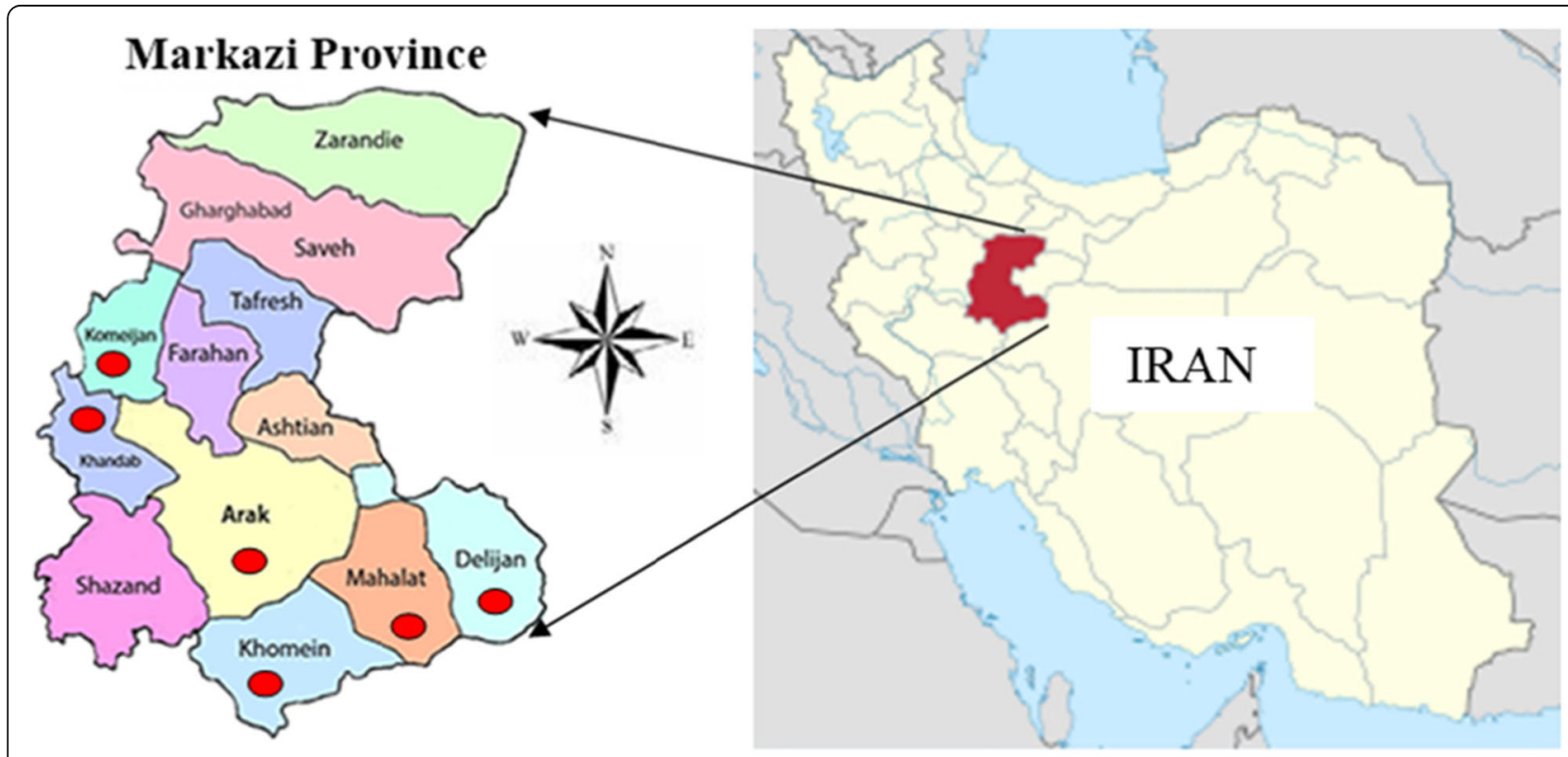

Fig. 1 Location of Markazi Province in the present prevalence study 
status as well as some risk factors of $T$. gondii including pregnancy and abortion history, and cat-care history. The $3 \mathrm{ml}$ blood samples were collected from the patients and coded using disposable sterile syringes under safety conditions.

Blood samples were kept overnight at ambient temperature in order to allow clot formation and were centrifuged at $1000 \mathrm{~g}$ for $10 \mathrm{~min}$ at room temperature. The obtained serum samples were collected in a 2-ml Eppendorf tubes and were stored at $4{ }^{\circ} \mathrm{C}$ for $24 \mathrm{~h}$ until transportation in an icebox to Parasitological Laboratory, School of Medicine, Arak University of Medical Sciences, Markazi Province where samples were kept at $-20^{\circ} \mathrm{C}$ until analysis [13].

\section{Serological test}

IgG anti-T. gondii antibody assay kit is designed with capture antibody method. Plate wells were coated with anti-human antibody. The levels of anti-Toxoplasma IgG antibodies were measured using a Pishtazteb kit according to the manufacturer's instructions. The optical density (OD) of the samples was measured at $450 \mathrm{~nm}$ and $630 \mathrm{~nm}$ using a plate reader (BioTek; Winooski, Vermont, USA). Index value larger than 1.1 was considered as positive. A range between 0.9 and 1.1 was considered as equivocal, and index value less than 0.9 was considered as negative. Positive and negative serum controls were included in every plate.

\section{Statistical analysis}

The SPSS software version 16 was used for statistical analysis. Data was presented as descriptive tables. The qualitative variables were also compared using the chisquare test. A $p$ value smaller than or equal to the 0.05 was considered as significant. Logistic regression tests were used to determine the relations between the risk factors of T. gondii infection and their incidence rates.

\section{Results}

In this study, 824 individuals were investigated. Table 1 shows the general characteristics of the studied population which their majority comprised urban married women aged 31-50 years.

Table 2 illustrates the prevalence of $T$. gondii infection in the counties of Markazi Province. It indicates that this disease is most prevalent in Arak with a contamination rate of $21.6 \%(p<0.05)$.

The results of the serological test showed that out of 824 blood samples from Markazi Province, 33.5\% had anti-Toxoplasma IgG antibodies (276 positive cases) and $66.5 \%$ did not have it (548 negative cases). Table 3 demonstrates the frequency of anti-Toxoplasma IgG antibodies in relation with the demographic characteristics of the studied population.
Table 1 Overview on the demographic characteristics of the population under study

\begin{tabular}{|c|c|c|}
\hline Percent (\%) & Numbers & Variables \\
\hline \multicolumn{3}{|l|}{$\overline{S e x}$} \\
\hline 65.2 & 537 & Female \\
\hline 34.8 & 287 & Male \\
\hline \multicolumn{3}{|c|}{ Age groups (year) } \\
\hline 15.7 & 129 & $20-30$ \\
\hline 29.9 & 247 & $31-40$ \\
\hline 32.8 & 270 & $41-50$ \\
\hline \multirow[t]{2}{*}{21.6} & 178 & $51-60$ \\
\hline & & Habitat \\
\hline 69.5 & 573 & Urban \\
\hline \multirow[t]{2}{*}{30.5} & 251 & Rural \\
\hline & & Marital status \\
\hline 11.5 & 95 & Single \\
\hline \multirow[t]{2}{*}{88.5} & 729 & Married \\
\hline & & Abortion history in women \\
\hline 17.1 & 92 & Yes \\
\hline \multirow[t]{2}{*}{82.9} & 445 & No \\
\hline & & Pregnancy history of women \\
\hline 70.9 & 381 & Yes \\
\hline \multirow[t]{2}{*}{29.1} & 156 & No \\
\hline & & Keeping cat \\
\hline 8.6 & 71 & Yes \\
\hline 91.4 & 753 & No \\
\hline
\end{tabular}

Table 3 represents the results of the adjusted regression model using gender variables including age (classified into four groups of 20-30 years, 31-40 years, $41-50$ years, and 51-60 years), place of residence (city or village), marital status (single or married), and having a cat at home.

Based on the results, only the age group variable played a role. This means that the variables of sex, location, marital status, and having a cat do not affect the chances of contracting the toxoplasma parasite.

We should notice that the age variable between 41-50 years $(p$ value $<0.05)$ remained notable in the model and it is not confirmed that the other age group coefficients have a remarkable level of $5 \%$.

According to the findings, the chance of contracting the toxoplasma parasite in people with age between 41 and 50 years is 0.85 times than the one in people with age between 20 and 30 years.

Although, the regression coefficient corresponding to the people with age between 31 and 40 years does not play a role in the adjusted regression model, the chance of contracting the parasite in this group of people is 1.37 times higher than in people with age between 20 and 30 years. 
Table 2 The prevalence of asymptomatic toxoplasmosis in the city of the Markazi Province

\begin{tabular}{llll}
\hline City & Seropositive samples (\%) & Seronegative samples (\%) & Total \\
\hline Arak & $178(21.6)$ & $421(51.2)$ & $599(72.8)$ \\
Khomain & $24(2.9)$ & $25(3)$ & $49(5.9)$ \\
Khondab & $6(0.73)$ & $42(5.1)$ & $48(5.8)$ \\
Mahallat & $25(3)$ & $23(2.8)$ & $48(5.8)$ \\
Komijan & $15(1.8)$ & $17(2.1)$ & $32(3.9)$ \\
Delijan & $28(3.4)$ & $20(2.4)$ & $48(5.8)$ \\
Total & $276(33.5)$ & $548(66.5)$ & $824(100)$ \\
\hline
\end{tabular}

Therefore, based on the results, the variables of sex, location, marital status, and having a cat do not affect the chances of contracting the toxoplasma parasite.

\section{Discussion}

This is the first cross-sectional study on seroprevalence of $T$. gondii infection among the general population of Markazi Province in central Iran. The basis of this study was the measurement of IgG in the serum of the studied subjects by ELISA method. Due to the role of humoral immunity in immune responses and infection prevention, IgG antibody measurement can be evaluated as an indicator to assess the personal immunity to the infection. Therefore, using the enzymatic immunoassay methods such as ELISA kit in diagnosing the level of immunity can be helpful.
The results of the present study showed that the prevalence of asymptomatic infection was $33.5 \%$ in the general population of Markazi Province. The comparison of the current results with those of previous studies in the same region of Iran (Arak city) showed that there was an approximate similarity in the prevalence of this disease between 1026 males who referred to a premarriage laboratory (35.5\%), 308 pregnant women (38\%), and 261 postpartum women in a maternity hospital (32.5\%). Contradictory, there was a sensible difference between the prevalence obtained in the present study and the serological prevalence of the disease in 400 girls of reproductive age $(24.3 \%)$ and 49 HIV-positive patients $(20.4 \%)$ in Arak city [7, 14].

A review of other sero-epidemiological studies of $T$. gondii in Iran showed that the prevalence of $T$. gondii

Table 3 Analysis of seroprevalence of toxoplasmosis based on some demographic characteristics of the population under study based on logistic regression

\begin{tabular}{|c|c|c|c|c|}
\hline Variables & Seropositive samples (\%) & Seronegative samples (\%) & OR & $p$ value \\
\hline \multicolumn{5}{|l|}{ Sex } \\
\hline Female & $177(33)$ & $360(67)$ & 0.934 & 0.657 \\
\hline Male & 99 (34.5) & $188(65.5)$ & & \\
\hline \multicolumn{5}{|c|}{ Age groups (year) } \\
\hline $20-30^{* *}$ & $37(28.7)$ & $92(71.3)$ & - & - \\
\hline $31-40$ & $56(22.8)$ & $191(77.2)$ & 1.37 & 0.475 \\
\hline $41-50$ & $87(32.2)$ & $183(67.8)$ & 0.846 & $0.0001^{*}$ \\
\hline $51-60$ & $96(53.9)$ & $82(46.1)$ & 0.344 & 0.074 \\
\hline \multicolumn{5}{|l|}{ Habitat } \\
\hline Urban & $194(33.9)$ & $379(66.1)$ & 1.055 & 0.739 \\
\hline Rural & $82(32.7)$ & $169(67.3)$ & & \\
\hline \multicolumn{5}{|c|}{ Marital status } \\
\hline Single & $27(28.4)$ & 68 (71.6) & 0.765 & 0.265 \\
\hline Married & $249(34.2)$ & $480(65.8)$ & & \\
\hline \multicolumn{5}{|c|}{ Keeping cat } \\
\hline Yes & $24(33.8)$ & $47(66.2)$ & 1.015 & 0.954 \\
\hline No & $252(33.5)$ & $501(66.5)$ & & \\
\hline
\end{tabular}

*Statistical significance was defined as a $p$ value of $<0.05$

**The reference category 
infection in the general population of Markazi Province is consistent with the one in the general population of Iran. The 23,385 cases out of 52,294 people who were investigated in different regions of Iran from the year 1978 to 2012, to identify anti-Toxoplasma IgG, tested positive. The meta-analysis of the available data showed that the prevalence of asymptomatic infection is in the range of $33-45.7 \%$ (with an average of $33.3 \%$ ) among the general population of Iran [8].

In a recent systematic review, Rostami et al. assessed the global prevalence of latent toxoplasmosis in pregnant women using published studies. They obtained a prevalence of $33.8 \%$ in this group of people. The countries with low income and low human development indices showed the highest prevalence [15]. In addition, in the published meta-analysis, the prevalence of $T$. gondii infection was assessed in immunocompromised individuals. Based on the results of this meta-analysis, the estimated pooled prevalence of toxoplasmosis in HIV-infected patients, cancer patients, and transplant recipients was reported as $42.1 \%, 26.0 \%$, and $42.1 \%$, respectively [16].

The serological prevalence of $T$. gondii infection in men and women in Markazi Province was 33\% and $34.5 \%$, respectively which is lower than what is reported as $42 \%$ in women and $44 \%$ in men in Iran [8]. It is noteworthy that in both provincial and national studies, the prevalence of asymptomatic is higher in men than in women. The meta-analysis of the available data showed that the prevalence of asymptomatic infection is in the range of $33-45.7 \%$ (with the average of $33.3 \%$ ) among the general population of Iran [8].

The mean prevalence of $T$. gondii infection in the age groups of $20-40$ and $\geq 40$ years was estimated to be $24.7 \%$, and $40.8 \%$, respectively which was significantly lower than the national result (44\%, and $55 \%$, respectively) [8].

The prevalence of $T$. gondii infection in the general population of Markazi Province like the one in the general population of Iran is significantly higher in people who are in contact with cats [8].

The prevalence of $T$. gondii infection in the current study was compared with the one found in similar studies in some adjacent provinces. In several studies on the prevalence of this parasite in Tehran the highest and the lowest prevalence rates were $68.4 \%$ [12], and $33.9 \%$ [17], respectively with an average of $49 \%$ [8]. This significant difference in the prevalence of $T$. gondii infection in this city is due to the socioeconomic status of the population in different parts of this metropolis. The prevalence of this disease in Isfahan Province was reported in three studies as $41.4 \%$ [18], 29.26\% [19], 51.25\% [20], and $50.8 \%$ [21] with an average of $40 \%$ [8]. According to our results, the prevalence of $T$. gondii infection in Markazi Province is almost similar to the one in Tehran
Province. The climatic similarity of these two provinces may also play a role in this prevalence rate similarity.

The comparison of the prevalence of $T$. gondii infection in Markazi Province with the other regions of the country showed that the prevalence of this disease in the province is very similar to the one in all climates except of the temperate and humid regions in northern Iran [11]. This result is not unexpected as Markazi Province has a diverse climates changing from mid-desert to cold mountainous [22].

Studeničová et al. reported a seroprevalence of $T$. gondii infection antibodies among 508 healthy individuals in Slovakia. Using the ELISA method for diagnosis, the prevalence of IgG antibody in the studied population was estimated to be $24.2 \%$ (123 out of 508 cases). This study also showed that the prevalence of $T$. gondii infection would increase significantly with age increasing. However, the prevalence of $T$. gondii infection in men and women as well as in rural and urban areas did not differ significantly [23].

Another study reported a high prevalence of IgG antibody in the inhabitants of Jakarta. The results indicated that the seroprevalence rate was $70 \%$ and there was no significant difference between men and women in the prevalence of $T$. gondii infection [24]. Alvarado-Esquivel et al. in 2011 reported that the prevalence of IgG antiT. gondii antibody in 974 inhabitants in Durango City in Mexico using the ELISA method was 6.1\% [25].

Another study using ELISA method in the rural area Okcheon-gun in Korea showed that the prevalence of $T$. gondii infection in women and men in the seventies or higher was significantly higher than in other groups. In accordance with the results of this study, we observed a correlation between increasing the prevalence of antibodies against $T$. gondii and age increasing. While our study showed a higher prevalence of $T$. gondii infection in women, this study did not show a significant difference in men (6.0\%) and women (7.2\%) [26].

In this study, we found that among all the investigated risk factors, only age had a significant effect on the outcome of contracting the parasite. In a study by $\mathrm{Li}$ et al., three variables including keeping cats at home, consuming uncooked meats, and the increasingly eating fresh oysters in recent years, were regarded to be risk factors for developing $T$. gondii infection in diabetic patients. Consumption of fresh oysters is common in recent years [27]. Nissapatorn et al. reported no significant relationship between the prevalence of toxoplasmosis and the related risk factors in expecting women [28]. Achaw et al. Remm reported that living in the city hand having minimal secondary education levels as major risk factors in $T$. gondii infection among pregnant women under prenatal care in downtown Babo Diolasso [29]. Adhroey et al. found that drinking untreated water to be a 
significant risk factor for higher T. gondii seroprevalence in China [30].

Our study has several limitations. Firstly, although both IgG and IgM antibodies are commonly studied in seroepidemiology of $T$. gondii studies, in this study the IgM measurement was excluded for three reasons as follows: (1) financial resource constraints, (2) the aim of the study which was to estimate the epidemiology of $T$. gondii in Markazi Province and not to diagnose and treat it, (3) detection of IgG but not IgM against $T$. gondii infection defines the classical serologic pattern of latent infection. In other word, IgG antibodies are used in epidemiological studies of chronic infectious diseases. Secondly, data analyzed in Markazi Province cannot be generalized to all provinces of the country. As these data are not real representations of the entire country of Iran, they cannot be compared to the results of national studies. Lastly, in order to compare the results with those obtained from other countries, data from a larger and more reliable statistical population in Iran should be collected.

\section{Conclusion}

To our knowledge this is the largest study of the seroepidemiology of $T$. gondii in the general population of the Markazi Province. Given the 33.5\% prevalence of asymptomatic infection in the general population of Markazi Province and regarding to the health authorities, it is necessary to raise the level of awareness of the people of the region, especially at-risk groups about the transmittance and prevention methods, and infection risk factors in order to prevent the occurrence of toxoplasma and reduce the prevalence and incidence of the disease.

\section{Abbreviations}

ELISA: Enzyme-linked immunosorbent assay; IgG: Immunoglobulin Gamma; IgM: Immunoglobulin M; HIV: Human immunodeficiency viruses

\section{Acknowledgements}

The authors thank the Student Research Committee of Arak University of Medical Sciences as well as Professor Daryani of Sari University of Medical Sciences.

\section{Authors' contributions}

This study was done by $M H, H S, R G, M D, M S, M M$, and MT. RG participated in the design of the study. Data collection was down by $R G, M H, M M$, and MT. Interpretation and manuscript preparation were conducted by RG. HS participated in the data editing. MS performed the statistical analysis. MD performed coordination and helped with the draft of the manuscript. All authors read and approved the final manuscript.

\section{Funding}

The authors gratefully acknowledge the Research Council of Arak University of Medical Science Project funding number is 545.

\section{Availability of data and materials}

Input data for the analyses are available from the corresponding author on request.

\section{Ethics approval and consent to participate}

The code of ethics of this study is the number IR.ARAKMU.REC.1396.15. We have obtained approval to conduct our study from the ethics committee of Arak University of medical science.

\section{Consent for publication}

Not applicable.

\section{Competing interests}

The authors declare that they have no competing interests.

\section{Author details}

${ }^{1}$ Student Research Committee, Arak University of Medical Sciences, Arak, Iran. ${ }^{2}$ Department of Infectious Diseases, Arak University of Medical Sciences, Arak, Iran. ${ }^{3}$ Departments of Parasitology and Mycology, Arak University of Medical Sciences, Arak, Iran. ${ }^{4}$ Department of Biostatistics, School of Public Health, Hamadan University of Medical Sciences, Hamadan, Iran. ${ }^{5}$ Department of Medical, Faculty of Nursing and Midwifery, Isfahan University of Medical Sciences, Isfahan, Iran. ${ }^{6}$ Department of Medical, Faculty of Nursing and Midwifery, Iran University of Medical Sciences, Tehran, Iran.

Received: 26 February 2020 Accepted: 4 May 2020

Published online: 19 May 2020

\section{References}

1. Robert-Gangneux F, Darde ML. Epidemiology of and diagnostic strategies for toxoplasmosis. Clin Microbiol Rev. 2012;25:264-96.

2. Djurkovic-Djakovic O, Dupouy-Camet J, Van der Giessen J, Dubey JP. Toxoplasmosis: overview from a one health perspective. Food Waterborne Parasitol. 2019;15:e00054.

3. Tenter AM, Heckeroth AR, Weiss LM. Toxoplasma gondii: from animals to humans. Int J Parasitol. 2000;30(12-13):1217-58.

4. Weiss LM, Dubey JP. Toxoplasmosis: a history of clinical observations. Int J Parasitol. 2009;39(8):895-901.

5. Burstein R, Henry NJ, Collison ML, Marczak LB, Sligar A, Watson S, et al. Mapping 123 million neonatal, infant and child deaths between 2000 and 2017. Nature. 2019;574(7778):353-8.

6. Sharbatkhori M, Moghaddam YD, Pagheh AS, Mohammadi R, Mofidi HH, Shojaee S. Seroprevalence of Toxoplasma gondii infections in pregnant women in Gorgan city, Golestan province, northern Iran-2012. Iran J Parasitol. 2014:9(2):181-7.

7. Aghaee R, Saki S, Didehdar M, Hajihossein R, Eslamirad Z. Epidemiologic evaluation of toxoplasmosis and leading risk factors in HIV/AIDS patients in Arak City. Iran Australasian Medical Journal. 2017;10(10):865-9.

8. Daryani A, Sarvi S, Aarabi M, Mizani A, Ahmadpour E, Shokri A, et al. Seroprevalence of Toxoplasma gondii in the Iranian general population: a systematic review and meta-analysis. Acta Trop. 2014;137:185-94.

9. Foroutan-Rad M, Khademvatan S, Majidiani H, Aryamand S, Rahim F, Malehi AS. Seroprevalence of Toxoplasma gondii in the Iranian pregnant women: a systematic review and meta-analysis. Acta Trop. 2016:158:160-9.

10. Mizani A, Alipour A, Sharif M, Sarvi S, Amouei A, Shokri A, et al. Toxoplasmosis seroprevalence in Iranian women and risk factors of the disease: a systematic review and meta-analysis. Trop Med Health. 2017;45:7.

11. Mostafavi $S$, Monfared L. Toxoplasmosis epidemiology in Iran: a systematic review. Journal of Isfahan Medical School. 2012;30(176):1-15.

12. Salahi-Moghaddam A, Hafizi A. A serological study on Toxoplasma gondii infection among people in south of Tehran. Iran Korean J Parasitol. 2009; 47(1):61-3.

13. Tian AL, Li GX, Elsheikha HM, Gardner DS, Zhang XY, Dong W, et al. Seroepidemiology of Toxoplasma gondii infection in patients with liver disease in eastern China. Epidemiol Infect. 2017;145(11):2296-302.

14. Mohammadi A, Shojaee S, Salimi M, Zareei M, Mohebali M, Keshavarz H. Seroepidemiological study of toxoplasmosis in women referred to Arak marriage consulting center during 2012-2013. Iran J Public Health. 2015; 44(5):654-8.

15. Rostami A, Riahi SM, Gamble HR, Fakhri Y, Nourollahpour Shiadeh M, Danesh M, et al. Global prevalence of latent toxoplasmosis in pregnant women: a systematic review and meta-analysis. Clin Microbiol Infect. 2020

16. Wang ZD, Liu HH, Ma ZX, Ma HY, Li ZY, Yang ZB, et al. Toxoplasma gondii infection in immunocompromised patients: a systematic review and metaanalysis. Front Microbiol. 2017:8:389. 
17. Abbasian L, Ranhbaran M, Talebi-Meymand F, Arab-Salmani F. Survey on toxoplasmosis effect on patients referred to health centers of Tehran according to height and weight. Proceeding of the 7th National and 2end regional congress of parasitology and parasitic disease in Iran 2010. 2010: Tehran University of Medical Sciences.

18. Mostafavi SN, Ataei B, Nokhodian Z, Yaran M, Babak A. Seroepidemiology of Toxoplasma gondii infection in Isfahan province, Central Iran: a population based study. J Res Med Sci. 2011;16(4):496-501.

19. Torkan S, Momtaz H, Abdizadeh R. Comparison of toxoplasmosis prevalence in individuals with and without cat contact in Isfahan using indirect immunofluorescent. J Shahrekord Univer Med Sci. 2008;10(3):83-9.

20. Pirali-Kheirabadi K, Tahmasebi H, Monjii H, Shafigh Z, Amiri-Dehcheshmeh J. Seroepidemiology of Toxoplasma gondii in Isfahan and Mazandaran provinces by ELISA method. Proceeding of the 7th National and 2nd RegionalCongress of Parasitology and Parasitic Disease in Iran Tehran University of Med-ical Sciences; 2012.

21. Arbabi M, Talari S, Asmar M, Rasti S. Seroepidemiology of toxoplasmosisin Kashan. Kashan Univ Med Sci. 1993;1:29-37.

22. Abedi B, Maghsood A, Khansarinejad B, Fallah M, Matini M, Gholami S, et al. Genotyping of Echinococcus granulosus isolates from livestock based on mitochondrial cox1 gene, in the Markazi Province, Iran. J Parasit Dis. 2019; 43(4):592-6.

23. Studenicova C, Bencaiova G, Holkova R. Seroprevalence of Toxoplasma gondii antibodies in a healthy population from Slovakia. Eur J Intern Med. 2006;17(7):470-3.

24. Terazawa A, Muljono R, Susanto L, Margono SS, Konishi E. High toxoplasma antibody prevalence among inhabitants in Jakarta, Indonesia. Jpn J Infect Dis. 2003;56(3):107-9.

25. Alvarado-Esquivel C, Estrada-Martinez S, Pizarro-Villalobos H, Arce-Quinones M, Liesenfeld O, Dubey JP. Seroepidemiology of Toxoplasma gondii infection in general population in a northern Mexican city. J Parasitol. 2011; 97(1):40-3.

26. Lee YH, Noh HJ, Hwang OS, Lee SK, Shin DW. Seroepidemiological study of Toxoplasma gondii infection in the rural area Okcheon-gun Korea. Korean J Parasitol. 2000;38(4):251-6.

27. Li YX, Xin H, Zhang XY, Wei CY, Duan YH, Wang HF, et al. Toxoplasma gondii infection in diabetes mellitus patients in China: seroprevalence, risk factors, and case-control studies. Biomed Res Int. 2018;2018:4723739.

28. Nissapatorn V, Lee CK, Cho SM, Rohela M, Anuar AK, Quek KF, et al. Toxoplasmosis in HIV/AIDS patients in Malaysia. Southeast Asian J Trop Med Public Health. 2003;34(Suppl 2):80-5.

29. Achaw B, Tesfa H, Zeleke AJ, Worku L, Addisu A, Yigzaw N, et al. Seroprevalence of Toxoplasma gondii and associated risk factors among psychiatric outpatients attending University of Gondar hospital Northwest Ethiopia. BMC Infect Dis. 2019;19(1):581.

30. Al-Adhroey AH, Mehrass AAO, Al-Shammakh AA, Ali AD, Akabat MYM, AlMekhlafi HM. Prevalence and predictors of Toxoplasma gondii infection in pregnant women from Dhamar Yemen. BMC Infect Dis. 2019;19(1):1089.

\section{Publisher's Note}

Springer Nature remains neutral with regard to jurisdictional claims in published maps and institutional affiliations.

Ready to submit your research? Choose BMC and benefit from:

- fast, convenient online submission

- thorough peer review by experienced researchers in your field

- rapid publication on acceptance

- support for research data, including large and complex data types

- gold Open Access which fosters wider collaboration and increased citations

- maximum visibility for your research: over $100 \mathrm{M}$ website views per year

At BMC, research is always in progress.

Learn more biomedcentral.com/submissions 